\title{
Efficient and robust biofabrication of silver nanoparticles by cassia alata leaf extract and their antimicrobial activity
}

\author{
Susmila Aparna Gaddam • Venkata Subbaiah Kotakadi • \\ D. V. R. Sai Gopal • Y. Subba Rao • \\ A. Varada Reddy
}

Received: 9 November 2013/ Accepted: 28 January 2014/Published online: 21 February 2014

(C) The Author(s) 2014. This article is published with open access at Springerlink.com

\begin{abstract}
Biosynthesis of green nanomaterials and their characterization comprise an emerging field of nanotechnology, due to their wide range of applications. The present study deals with the synthesis of silver nanoparticles (AgNPs) using an aqueous leaf extract of Cassia alata. The AgNPs are characterized using UV-Visible spectroscopy. The surface plasmon resonance spectrum of AgNPs was obtained at $434 \mathrm{~nm}$, and scanning electron microscopy coupled with X-ray energy dispersive spectroscopy (EDX) data revealed that AgNPs were uniformly spherical in shape. EDX data show very strong silver signal and weak signals to other elements, and X-ray diffraction patterns reveal that the particles are crystalline in nature with facecentered cubic structure. Fourier transform-infrared spectroscopy reveals that the carbonyl group $(\mathrm{C}=\mathrm{O}$, $1637.07 \mathrm{~cm}^{-1}$ ) is involved in the reduction of $\mathrm{Ag}^{+}$to $\mathrm{Ag}$. The synthesized AgNPs were crystalline in nature and spherical in shape, with an average of $>41 \mathrm{~nm}$ size. The stability of AgNPs is due to its high negative zeta potential, which is $-50.7 \mathrm{mV}$. Further, atomic force microscopy studies also revealed that the average particle size was
\end{abstract}

S. A. Gaddam and V. S. Kotakadi contributed equally to the work.

S. A. Gaddam $(\bowtie) \cdot$ D. V. R. Sai Gopal

Department of Virology, Sri Venkateswara University,

Tirupati 517502, Andhra Pradesh, India

e-mail: susmilaaparna@gmail.com

V. S. Kotakadi ( $\square)$

DST-PURSE Centre, Sri Venkateswara University,

Tirupati 517502, Andhra Pradesh, India

e-mail: kotakadi72@gmail.com

Y. Subba Rao · A. Varada Reddy

Department of Chemistry, Sri Venkateswara University,

Tirupati 517502, Andhra Pradesh, India
$47 \mathrm{~nm}$ which correlates with the above result of particle size analysis. The present study also indicates that AgNPs have considerable antibacterial activity and exceptionally superior antifungal activity, in comparison with standard antimicrobial drugs.

Keywords Green synthesis - Cassia alata AgNPs . Spectral analysis - Antimicrobial activity

\section{Background}

Green synthesis of nanomaterials is a promising area, due to its applications in the fields of physics, chemistry, biology and medicine. The synthesized nanomaterials have been used widely in medicinal and technological aspects. There are a number of approaches available for the synthesis of silver nanoparticles, for example, reduction of solutions [1], chemical and photochemical reactions [2], thermal decomposition of silver compounds [3], radiationassisted [4], electrochemical [5], sonochemical [6] and microwave-assisted processes [7], use of bacteria [8], fungi [9] and enzymes [10], and recently via the green chemistry route [11-13]. The use of environmentally benign materials like plant leaf extract [14-20] for the synthesis of silver nanoparticles offers numerous benefits which are compatible with various pharmaceutical and biomedical applications. The presence of some toxic chemicals adsorbed on the surface of the nanoparticles that are synthesized by chemical methods may have adverse effect on the biomedical applications. Thus, 'green synthesis' is an apt method, safer than the chemical and physical method. Green synthesis is effective, eco-friendly and without difficulty scaled up on a large scale. There is no need of high pressure, energy, temperature and toxic chemicals. 
The inhibitory effect of silver on microbes, which was detected in the past, is generally used in medical and industrial processes [21, 22]. The most important application of silver and silver nanoparticles is in medical industries, in such medicines as topical ointments to prevent infection against burns and open wounds [23].

In the present study, we report the synthesis of silver nanoparticles by an aqueous leaf extract of Cassai alata for the first time. These biologically synthesized nanoparticles were found to be extremely effective against different bacterial and fungal pathogens. The common name for Cassai alata is candle bush, wild senna, ringworm senna, etc. (Fig. 1). It belongs to the family Caesalpiniaceae, a tropical annual herb consisting of leathery, compound leaves. The leaves have laxative properties and very good antimicrobial and antifungal activity. The leaves are extensively used against dermatophyte infections, such as 'tidea foot,' popularly known as 'athlete foot', for superficial mycoses and also in the treatment of chronic fungal infections such as 'pityriasis versicolor'. They are used externally for the treatment of skin disease, acne, tinea infections, insect bites, ringworms, eczema, scabies, itchiness, and internally as expectorant for bronchitis, for alleviation of asthma symptoms, as a laxative to expel intestinal parasites, for stomach problems and weight loss [24-26]. In the present study, Cassia alata was used for the synthesis of silver nanoparticles by the green route and characterized by spectral analysis.

\section{Results and discussion}

Cassia alata is known to contain some secondary metabolites such as resin, saponin, phenols, flavonoids, anthraquinone glycosides and alkaloids [24] and it is also useful

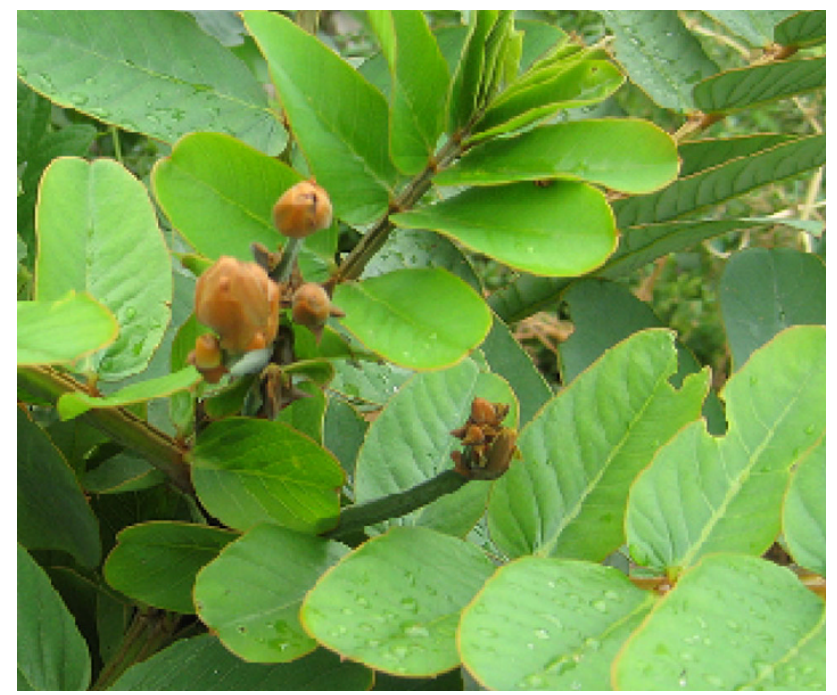

Fig. 1 Cassia alata plant showing leaves and inflorescence in the treatment of eruptive and pustular skin conditions, which can be cured by rubbing crushed fresh leaves on the infected area. [24] These phytoconstituents are also known to possess surface activity and other soap-related properties. In previous studies, Cassia alata has been found to possess excellent wound-healing properties $[25,26]$. The water-soluble ingredients present in the extract are responsible for the reduction of metal ions and efficient stabilization of nanoparticles.

\section{UV-Vis analysis of Ag nanoparticles}

UV-Vis spectroscopy is an important technique for analyzing the formation of silver nanoparticles in aqueous solution. AgNPs have free electrons, which give rise to a surface plasmon resonance (SPR) absorption band, due to the combined vibration of electrons of the metal nanoparticles in resonance with the light wave. A surface plasmon resonance spectrum of AgNPs was obtained at $434 \mathrm{~nm}$ after 10 min with the color changing to light yellow brown (Fig. 2a, b). The UV-visible spectrum of AgNPs and its excitation also depending upon the particle size [27].The earlier reports showed that the absorption peaks around $390-420 \mathrm{~nm}$ and above can be attributed to AgNPs in the size range of 25-50 nm [28]. Previous report also reveals that the particles in the SPR region of around $410-450 \mathrm{~nm}$ can be attributed to spherical nanoparticles [27, 29, 30]. In the present study, the SPR of AgNPs is $434 \mathrm{~nm}$ (Fig. 3) and the size of the particles is determined at around 22 to $48 \mathrm{~nm}$. The particles are spherical in shape, which is

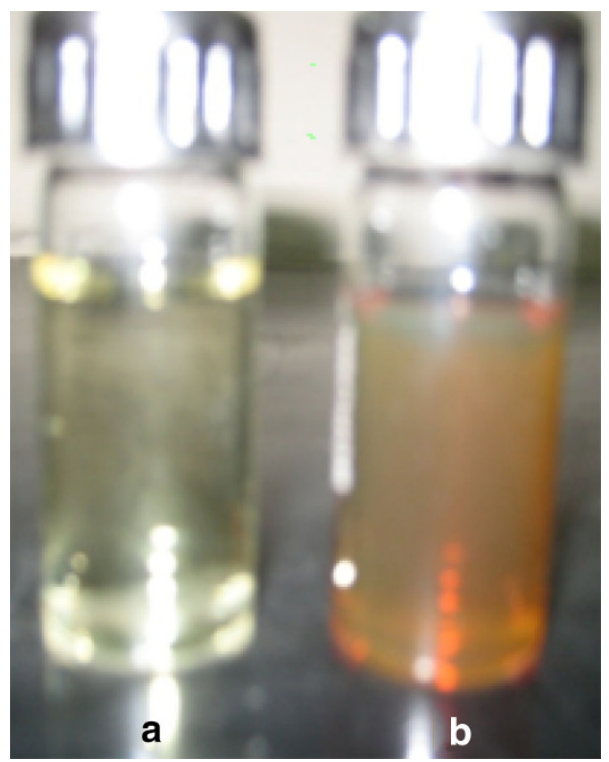

Fig. 2 a Aqueous extract of Cassia alata. b AgNPs solution after addition of extract to $\mathrm{AgNO}_{3}$ solution 


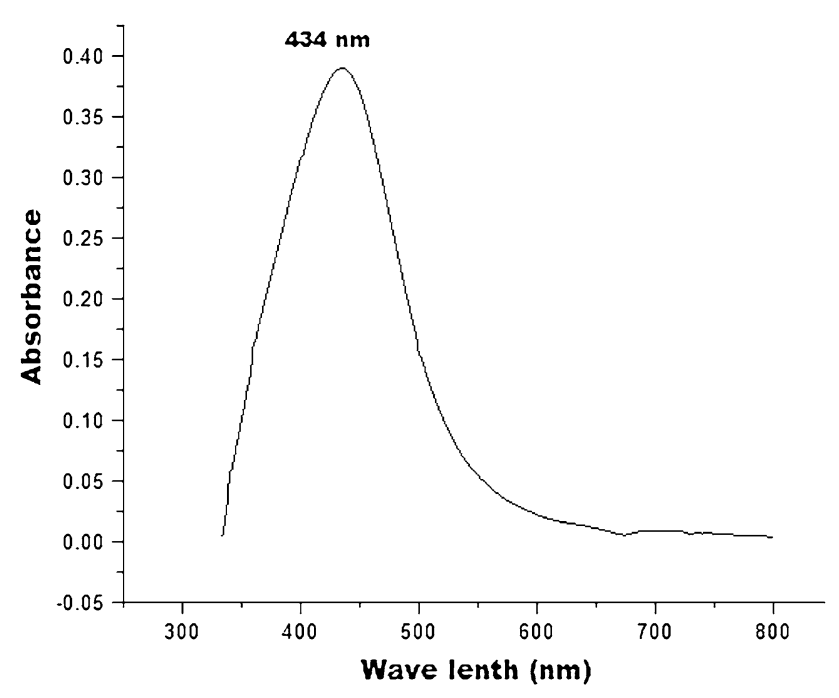

Fig. 3 UV-VIS absorbtion spectra of AgNPs synthesized from Cassia alata leaves extract with $2 \times 10^{-3} \mathrm{M}$ silver nitrate further confirmed by scanning electron microscopy (SEM), particle size analysis and atomic force microscopy (AFM) studies.

\section{SEM and EDX analysis of AgNPs}

The morphology of the synthesized AgNPs was determined by SEM images (Fig. 4a), which show that the AgNPs are uniformly spherical in shape. The energy dispersive spectroscopy (EDX) data show very strong silver, oxygen and carbon signals and weak signals of chlorine and aluminum peaks, which indicate that the reduction of silver ions to elemental silver possibly originated from the molecules attached to the surface of the AgNPs (Fig. 4b). Similarly according to an earlier report, silver nanoparticles showed an EDX spectrum, with emission energy at $3 \mathrm{keV}$ for silver and weak signals for other elements [31].
Fig. 4 a SEM micrograph of synthesized AgNPs. b EDX spectrum of synthesized AgNPs

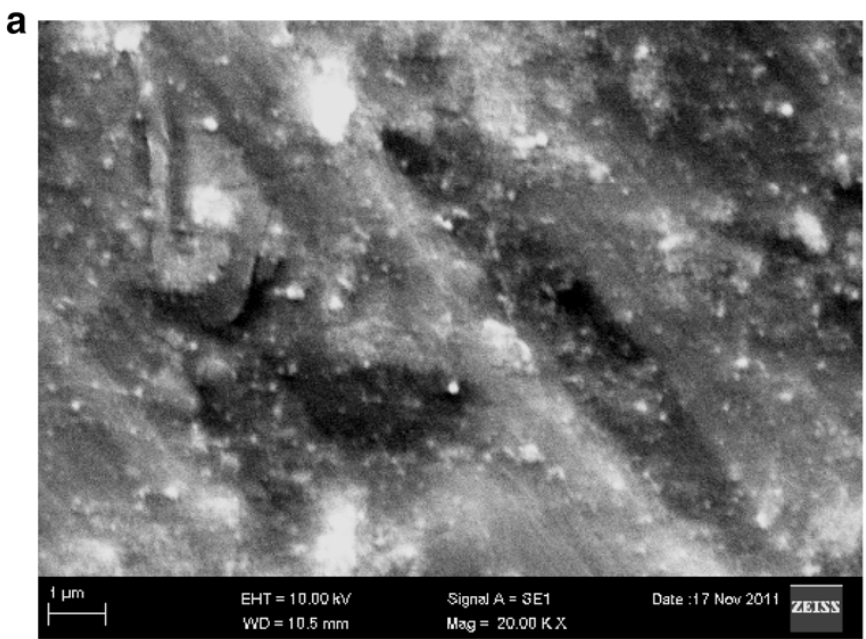

b

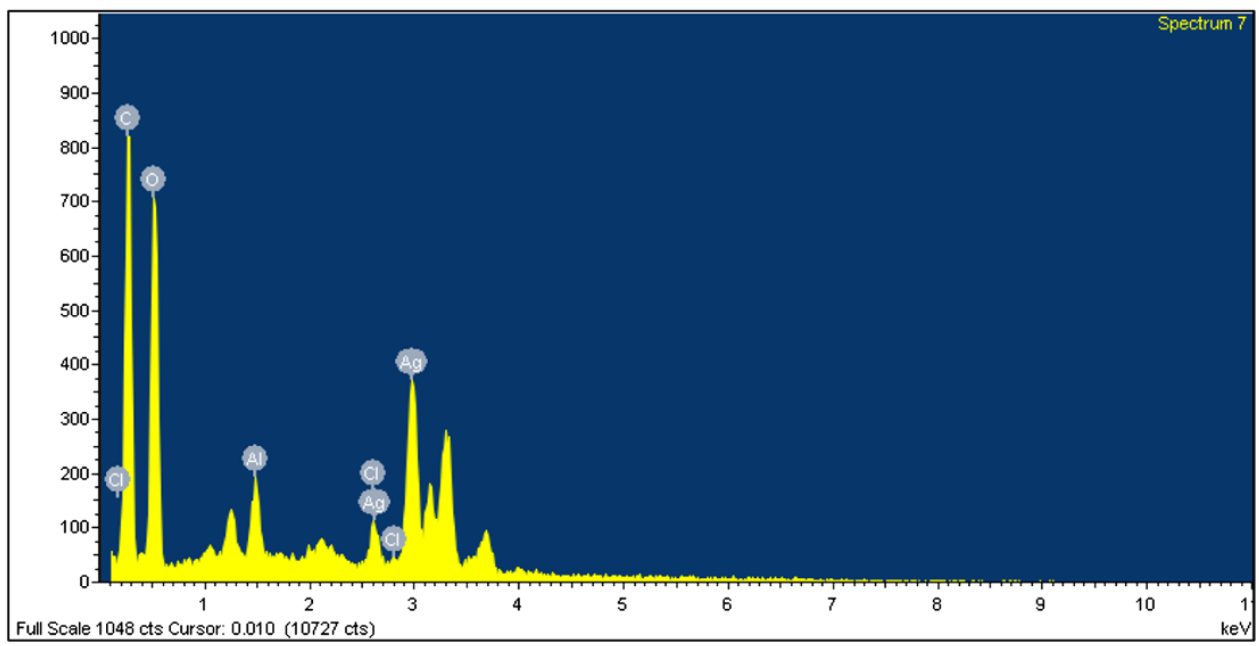




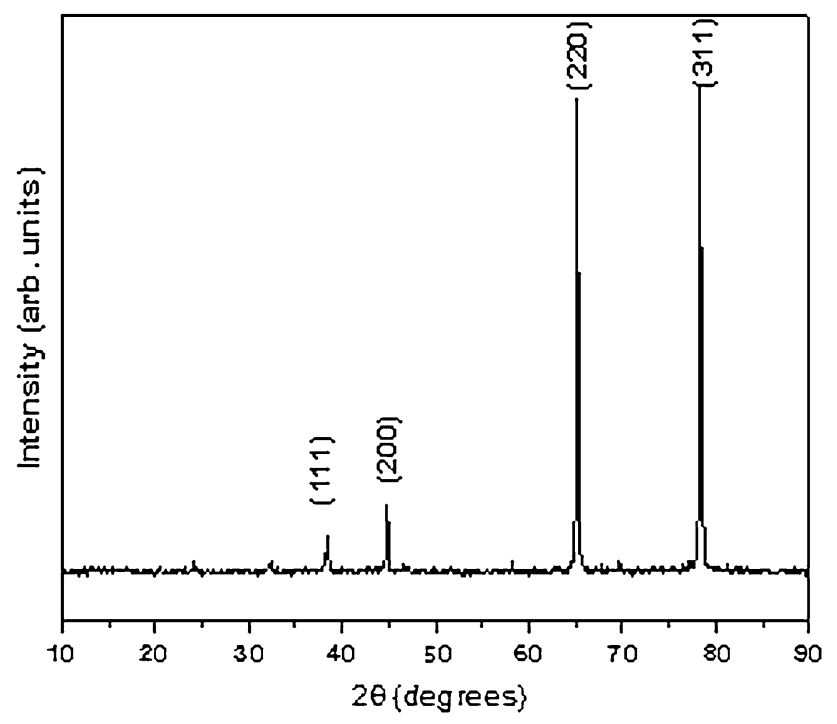

Fig. 5 XRD analysis of the synthesized AgNPs

\section{XRD}

The crystalline nature of the green synthesized AgNPs by Cassia alata leaf extract was also confirmed by X-ray diffraction patterns (XRD) pattern analysis. The XRD pattern (Fig. 5) indicates the face-centered cubic structure of the AgNPs. There are four distinct reflections in the diffractogram at $38.5^{\circ}(111), 44.7^{\circ}(200), 65.1^{\circ}(220)$ and $78.3^{\circ}$ (311) (JCPDS Card No. 03-0931). The absence of any additional reflections other than the reflections belonging to the Ag lattice clearly suggests that the green synthesized Ag NP lattice was unaffected by other molecules in the plant extract [32].

\section{FT-IR spectral analysis}

Fourier transform-infrared (FT-IR) analysis was performed to identify the possible biomolecules responsible for the reduction of the Ag+ ions and capping of the reduced silver nanoparticles. Strong IR bands were observed at $3465,2088,1635,564$ and $522 \mathrm{~cm}^{-1}$. The bands which appeared at 3465 and $2,088 \mathrm{~cm}^{-1}$ corresponded to $-\mathrm{OH}$ stretching and aliphatic $-\mathrm{C}-\mathrm{H}$ stretching, respectively [33]. The bands at $1,635 \mathrm{~cm}^{-1}$ is due to the $\mathrm{C}=\mathrm{O}$ and $\mathrm{C}=\mathrm{C}$ stretching, respectively. The low band at $590 \mathrm{~cm}^{-1}$ corresponds to $\mathrm{C}-\mathrm{Cl}$ stretching. Hence, Cassia alata is known to contain some secondary metabolites such as resin, saponin, phenols, flavonoids, anthraquinone glycosides and alkaloids in the Cassia alata leaf [24]. The IR spectrum of the silver nanoparticles is shown in Fig. 6. The spectrum reveals that the carbonyl group $\left(\mathrm{C}=\mathrm{O}, 1635 \mathrm{~cm}^{-1}\right)$ and $-\mathrm{OH}$ stretching and the aliphatic group $(-\mathrm{C}-\mathrm{H}$ stretching of 3465 and $2,088 \mathrm{~cm}^{-1}$ ), are involved in the reduction of $\mathrm{Ag}^{+}$to $\mathrm{Ag}$. Therefore, it may be concluded that flavonoids, alkaloids and anthraquinones are responsible for capping and efficient stabilization.

\section{Particle size determination}

The particle size of AgNPs obtained was detected by intensity and laser diffraction which are polydispersed in mixture solution. The size of synthesized AgNPs ranges from 22 to $48 \mathrm{~nm}$ and the average diameter of the AgNPs were found to be $>42 \mathrm{~nm}$. (Fig. 7a).
Fig. 6 IR spectrum of the synthesized AgNPs

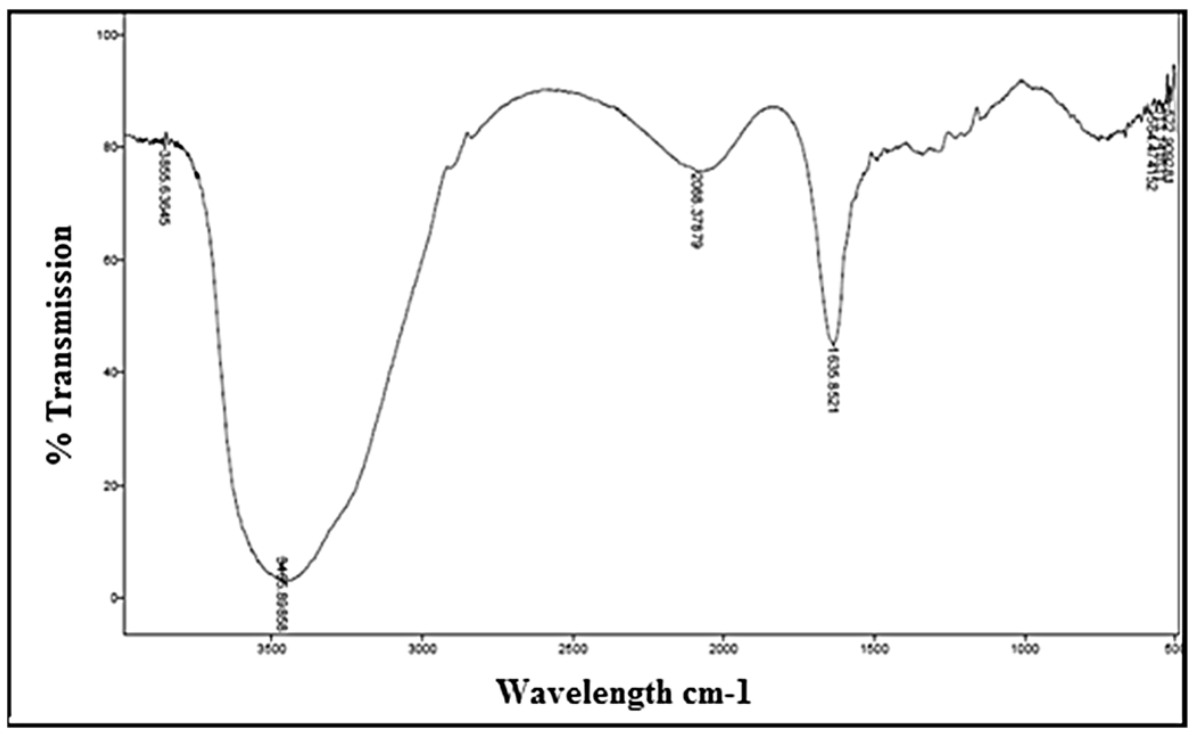




\section{Zeta potential measurement}

The higher negative value of zeta potential confirms the repulsion among the particles and thereby increases the stability of the formulation. The electrostatic repulsive forces between the nanoparticles when they are negatively charged possibly protect them from forming an association. This prevents the particles from agglomeration in the medium leading to long-term stability [34]. The AgNPs in the present study were negatively charged with a zeta potential of $-50.7 \mathrm{mV}$ (Fig. $7 \mathrm{~b}$ ), which proves that the particles were dispersed in the medium, proving the verdict that they are stable.

\section{Morphological studies of silver nanoparticles by AFM}

The AFM results indicated that the surface topology of the synthesized silver nanoparticles was spherical in shape, and it was also found that the deposited silver nanoparticles formed aggregates on the surface of the aluminum foil. The size of the synthesized AgNPs varied from 20 to $52 \mathrm{~nm}$, but the average grain size of the nanoparticles was detected as $47.934 \mathrm{~nm}$. (Fig. 8a, b) The maximum area peak height is $44.676 \mathrm{~nm}$, whereas the maximum area of valley depth is $51.192 \mathrm{~nm}$. Sa, the average roughness of the particles is $9.277 \mathrm{~nm}$ and, $\mathbf{S q}$, the root mean square roughness is $12.138 \mathrm{~nm}$. Further, SEM studies also revealed that the silver nanoparticles were mostly spherical in morphology.

\section{Antimicrobial activity}

Though there are many reports regarding antimicrobial activity of AgNPs biosynthesized by plant materials, in most of the cases the plant extract showed minimum or no inhibition, whereas the synthesized AgNPs showed minimum to moderate and good to excellent activity [15, 17-22]. The past studies reveal that different concentrations of AgNPs are more effective against $S$. aureus than E. coli [35], whereas Ruparelia et al. [36] determined the AgNPs against four different strains of $E$. coli and three different strains of $S$. aureus. Lukman et al. also worked on the antimicrobial and antibacterial properties of Ag nanoparticles [37] against Salmonella, Shigella and Proteus. So, the present study deals with the synthesis of AgNPs using
Fig. 7 a Particle size distribution curve for AgNPs. b Zeta potential of synthesized AgNPs
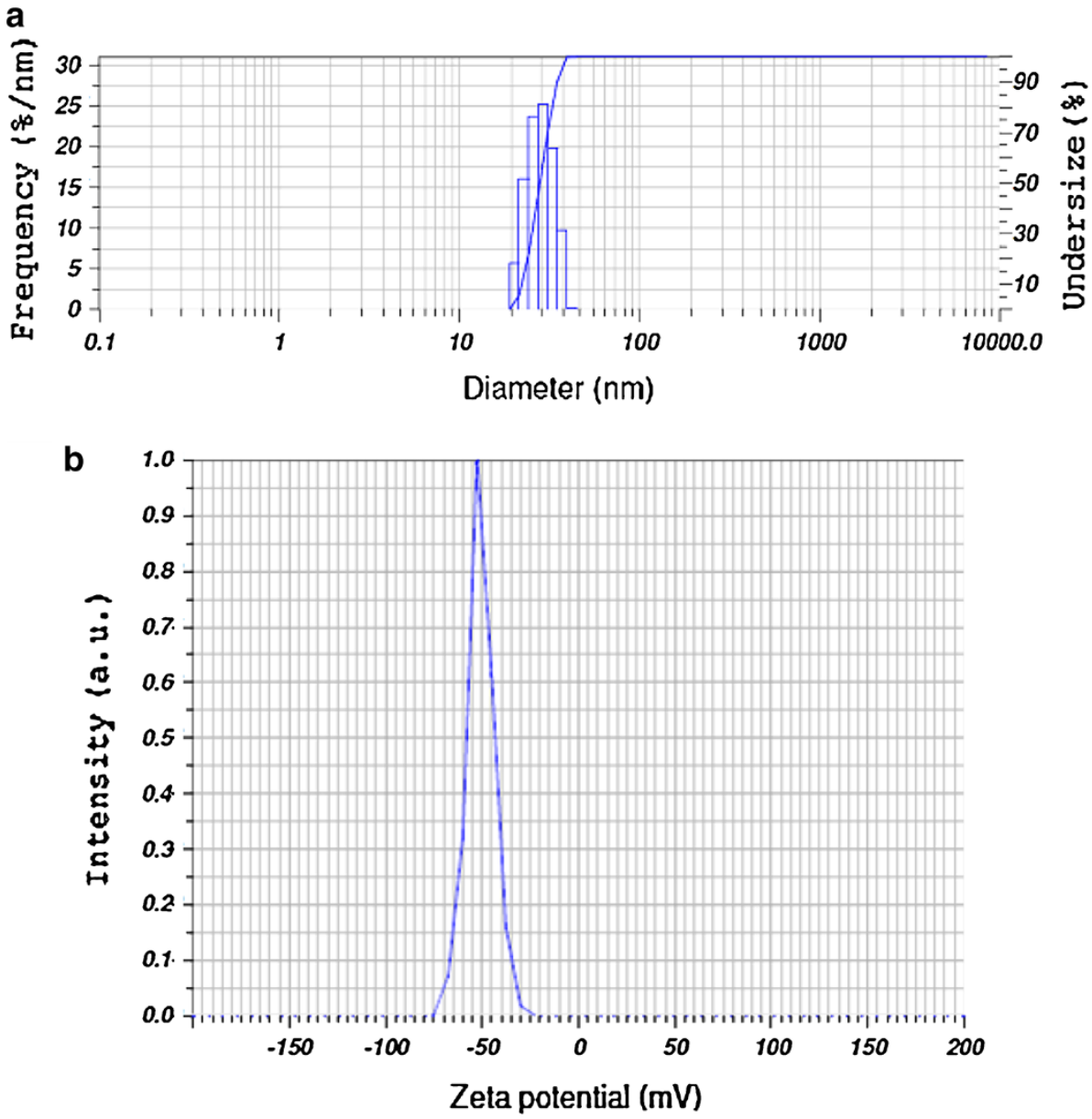

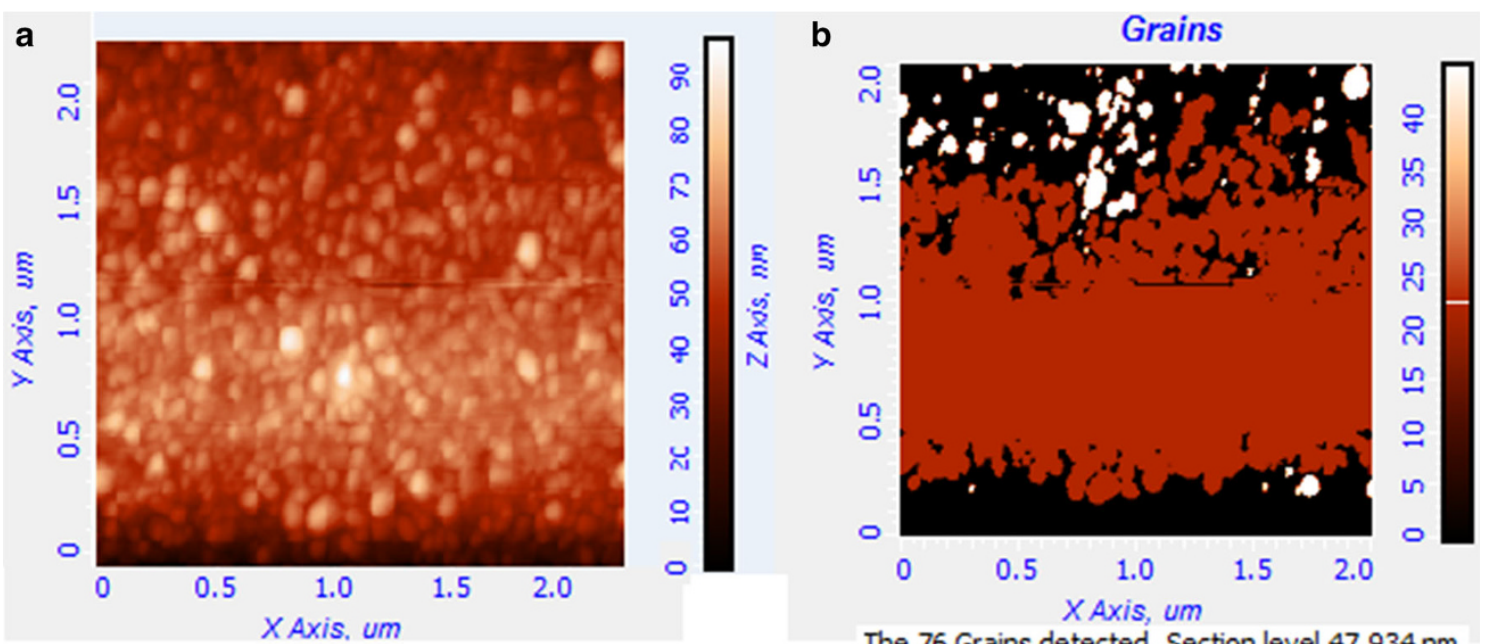

The 76 Grains detected. Section level $47.934 \mathrm{~nm}$

Fig. 8 a 2D image of synthesized AgNps. b Grains detected

leaf extract of Cassia alata and studies the antimicrobial activity of these nontoxic nanomaterials.

The AgNPs synthesized by green route were found to be very destructive against four bacterial species at a concentration of $10 \mu \mathrm{l}$ : Gram-positive Staphylococcus aureus and Lactobacillus and Gram-negative Escherichia coli and Pseudomonas fluorescens. It revealed higher antibacterial activity against Pseudomonas fluorescens, where as intermediate activity was revealed against Escherichia coli, Staphylococcus aureus and lactobacillus. The inhibitory activities of the AgNPs are reported in Table 1 and were comparable with reference drug viz. Amoxyclav (Himedia SD063). The antimicrobial activity of silver has been recognized by clinicians for over 100 years. It is only in the past few decades that the mode of action of silver as an antimicrobial agent has been studied [38]. Several people have also investigated the antibacterial activity of biosynthesized silver nanoparticles against Staphylococcus aureus, Escherichia coli, P. aeruginosa and K. pneumonia. [15, 18-22, 35, 36, 39] Similarly, Kim et al. [40] have reported the antimicrobial activity of silver nanoparticles against E. coli and $S$. aureus. The synthesized AgNPs exhibited very good antibacterial activity against both Gram-positive (Staphylococcus aureus, Lactobacillus) and Gram-negative bacteria (Escherichia coli, Pseudomonas fluorescens) and formed the zone of inhibition of diameters $13,12,14$ and $15 \mathrm{~mm}$, respectively; the leaf extract also had moderate antimicrobial activity zone of inhibition of diameters 07, 06, 09 and $09 \mathrm{~mm}$, respectively (Table 1). The electrostatic attraction of AgNPs with bacterial cells causes damage to the bacterial cell membrane; thus the formation of pores occurs on the surface which causes structural changes in bacterial cells and subsequently cell death. Thus, the zone of inhibition increases with increasing concentration of
Table 1 Antibacterial and fungal activity of the synthesized silver nanoparticles

\begin{tabular}{|c|c|c|c|c|}
\hline & \multirow{3}{*}{$\begin{array}{l}\text { Leaf } \\
\text { Extract }\end{array}$} & \multirow{3}{*}{$\begin{array}{l}\text { Silver nitrate } \\
\text { solution }\end{array}$} & \multirow{2}{*}{\multicolumn{2}{|c|}{$\frac{\text { Cassia alata }}{\text { Inhibition zone }}$}} \\
\hline & & & & \\
\hline & & & Control & AgNPs \\
\hline \multicolumn{5}{|l|}{ Bacterial species } \\
\hline Bacillus sp. & 07 & - & 15 & 13 \\
\hline Lactobacillus & 07 & - & 15 & 12 \\
\hline $\begin{array}{l}\text { Staphylococcus } \\
\text { aureus }\end{array}$ & 09 & - & 16 & 14 \\
\hline $\begin{array}{l}\text { Pseudomonas } \\
\text { fluorescens }\end{array}$ & 09 & - & 18 & 15 \\
\hline \multicolumn{5}{|l|}{ Fungal species } \\
\hline Aspergillus niger & 08 & - & 15 & 18 \\
\hline Penicillium sp. & 09 & - & 16 & 20 \\
\hline
\end{tabular}

silver nanoparticles [41]. In prokaryotic bacteria, the AgNPs interact with the bacterial cell membrane, bind with mesosome cell organelle, reduce mesosomal function and increase the reactive oxygen species (ROS) generation. The silver nanoparticles interact with thiol groups in protein; thus, inactivation of protein synthesis as well as DNA replication takes places [42]. At the same time the oxygen associates with silver and reacts with the sulfhydryl $(-\mathrm{S}-\mathrm{H})$ groups on the bacterial cell wall to remove the hydrogen atoms, causing the sulfur atoms to form an $\mathrm{R}-\mathrm{S}-\mathrm{S}-\mathrm{R}$ bond, thus blocking the respiration within the cell and causing a lethal effect on bacterial cells [43]. The silver nanoparticles naturally interact with the cell membrane of bacteria and disrupt the membrane integrity. Thus, silver ions bind to sulfur, oxygen and nitrogen of essential biological molecules and inhibit bacterial growth [44]. 


\section{Antifungal activity}

Further studies of AgNPs synthesized by the green route have shown them to be extremely toxic against two fungal species at a concentration of $10 \mu \mathrm{l}$, and revealed exceptional antifungal activity against Aspergillus niger and penicillium sp. The inhibitory activities of AgNPs reported in Table 1 were comparable with the reference drug, viz. Fluconazole $\mathrm{Fu}^{10}$ (SD114, Himedia). The zone of inhibition of AgNPs against Aspergillus niger and penicillium sp. is 18 and $20 \mathrm{~mm}$ in diameter, when compared with standard drug Fluconazole $\mathrm{Fu}^{10}$ it is 15 and $16 \mathrm{~mm}$ in diameter, respectively. At the same time we have tested the activity of the leaf extract against Aspergillus niger and penicillium $\mathrm{sp}$. and the zone of inhibition is 08 , and $09 \mathrm{~mm}$ in diameter. The leaf extract also showed very good antifungal activity as reported earlier [24]. On comparing the results, we finally conclude that the synthesized AgNPs have very good antifungal activity than the leaf extract and standard drug. (Table 1) Thus, synthesized AgNPs have the most important applications in medical industry for the preparation of antibacterial and antifungal tropical ointments [23].

\section{Conclusion}

Cassia alata leaf extract is found to be appropriate for rapid extraction of AgNPs by green synthesis within $10 \mathrm{~min}$. The spectroscopic characterization from UV-Vis, SEM and EDX, XRD, particle size analysis, zeta potential and AFM analysis reveals the formation of stable AgNPs by the green route, which are highly stable and polydispersed in nature. The average size of AgNPs was found to be $45 \pm 3 \mathrm{~nm}$. The biosynthesized nanoparticles are useful in various biomedical and biotechnological applications. We conclude that the AgNPs have excellent antimicrobial activity when compared with standard drug as well as other synthesized nanoparticles with various plant sources. The AgNPs are prepared in a simple and cost-effective manner, suitable for the formulation of new types of antimicrobial materials.

\section{Methods}

Synthesis of silver nanoparticles

The Cassia alata leaves were collected from trees growing in the fields in and around Tirupati, Andhra Pradesh, India. The leaves were shade dried for 7 days at room temperature. The plant leaf extract was prepared by taking $1 \mathrm{~g}$ of finely powdered leaves in a $250 \mathrm{ml}$ Erlenmeyer flask, with $100 \mathrm{ml}$ of double-distilled water. The mixture was boiled for $5 \mathrm{~min}$ and filtered first through sterile muslin cloth and Whatman filter paper before finally decanting it. The filtrate was used for the preparation of silver nanoparticles. This filtrate solution was used as the source extract and utilized in subsequent procedures (Fig. 2a). To the $5 \mathrm{ml}$ diluted filtrate, $10 \mathrm{ml}$ of $0.025 \mathrm{M} \mathrm{AgNO}_{3}$ was added and the sample was left at room temperature, until the color of the solution changed from light yellow to brown (Fig. 2b). The presence of AgNPs in the solution was confirmed by a dark brown color. In the present process, silver nanoparticles were produced with Cassia alata plant leaves extract in aqueous solution without any external, man-made chemicals. Therefore, this method or pathway satisfies the green chemical process $100 \%$ (schematic diagram of bioreduction for formation of $\mathrm{AgNPs}$ ).

\section{Characterization}

The bioreduction of pure $\mathrm{Ag}+$ ions with the leaf extract of Cassia alata was monitored periodically by sampling the $1 \mathrm{ml}$ aliquots and the optical absorbance of silver

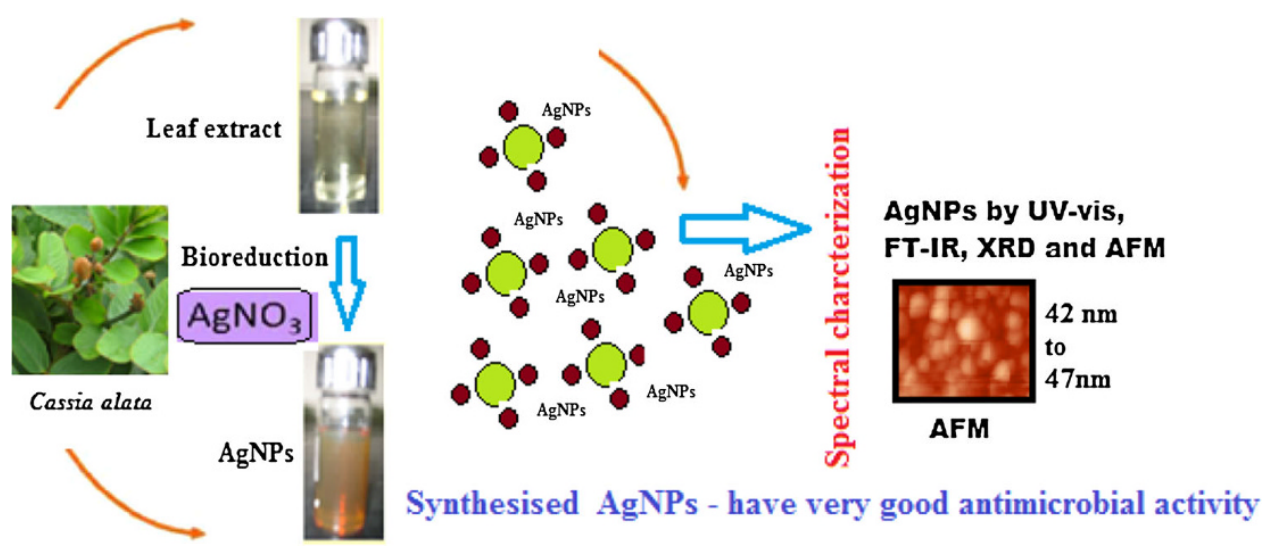


nanoparticles suspended in distilled water was recorded on a UV-Vis spectrophotometer (Shimadzu 2400 UVVis double beam model) in the 200-800 $\mathrm{nm}$ wavelength range. The reactions were carried out at room temperature on a spectrophotometer at a resolution of $1 \mathrm{~nm}$. Scanning electron microscopy (SEM) and EDX were performed by Oxford Inca Penta FeTX3 EDS instrument attached to Carl Zeiss EVO MA 15 Scanning Electron Microscope $(200 \mathrm{kV})$ machine with a line resolution 2.32 (in $\AA$ ). These images were taken by drop coating AgNPs on an aluminum foil. Energy dispersive absorption spectroscopy photograph of AgNPs was carried out by the SEM equipment, as mentioned above. The X-ray diffraction (XRD) pattern measurements of drop-coated film of AgNPs on aluminum foil substrate were recorded at a wide range of Bragg angles $2 \theta$ at a scanning rate of $2 \min ^{-1}$ and carried out on a spectroscopy using Seifert Rayflex 300TT X-ray diffractometer with $\mathrm{CuK}$ $(\lambda=1.542 \AA)$ radiation that was operated at a voltage of $40 \mathrm{kV}$ and a current of $30 \mathrm{~mA}$ with $\mathrm{CuK}(\lambda=1.545 \AA)$ radiation. The FT-IR was carried using Shimadzu IR instrument; particle size and zeta potential measurement experiments were carried out using a Nanopartica (HORIBA instrument). Morphological studies of silver nanoparticles were also done using AFM. A drop of synthesized AgNPs suspension was placed on thin aluminum sheet and dried at room temperature, prior to the analysis of the sample in atomic force microscopy (AFM-Solver Next, NT-MDT, Russia).

\section{Antimicrobial activity}

The antimicrobial activity of silver nanoparticles was evaluated against Gram-positive Staphylococcus aureus and Lactobacillus and Gram-negative Escherichia coli and Pseudomonas fluorescens by the disc method. The 24-h-old cultures were prepared in nutrient broth (composition $(\mathrm{g} / \mathrm{l})$. Two replicas of the respective microorganisms were prepared by spreading $100 \mu \mathrm{l}$ of revived culture on the nutrient agar plate (composition (g/l) peptone, yeast extract, sodium chloride, D (+) glucose and agar-agar) with the help of a spreader. Discs were prepared using Whatman No.1 filter paper. The discs were placed on agar plates and a sample of synthesized silver nanoparticles was added to the disc with the help of a micropipette. The plates were incubated at $37{ }^{\circ} \mathrm{C}$ overnight. Amoxyclav (Himedia SD063) disc was used as a reference drug. Different bacterial strains maintained on nutrient agar and subcultures were freshly prepared before use. Bacterial cultures were prepared by transferring two to three colonies into a tube containing $20 \mathrm{ml}$ nutrient broth and grown overnight at $37{ }^{\circ} \mathrm{C}$.
Antifungal activity

Sterile potato dextrose agar medium was prepared and poured into sterile Petri plates and allowed to solidify; after solidification, fungal cultures were swabbed on these plates. The sterile discs were dipped in AgNPs solution, placed on the agar plate and kept for incubation for 7 days. After 7 days the discs dipped in plant extracts and $0.025 \mathrm{M}$ silver nitrate solution were also placed on the agar plates along with AgNPs as control to compare the results.

Acknowledgments The authors are grateful to DST-PURSE, Department of Science and Technology, New Delhi, for the research fellowships, to work under PURSE Programme at Sri Venkateswara University, Tirupati. The authors are grateful to the Regional Agricultural Research Station, ANGRU, Tirupati, for extending the particle size and zeta potential analysis facility.

Conflict of interest The authors declare that they have no competing interests.

Author contribution VSK and SAG carried out the nanoparticles synthesis, characterization and antimicrobial activity. YS carried out FTIR studies. VSK and SAG carried out the manuscript preparation. All authors read and approved the final manuscript.

Open Access This article is distributed under the terms of the Creative Commons Attribution License which permits any use, distribution, and reproduction in any medium, provided the original author(s) and the source are credited.

\section{References}

1. Goia, D.V., Matijevic, E.: N: Preparation of monodispersed metal particles. J Chem 22, 1203-2015 (1998)

2. Taleb, C., Petit, M., Pileni, P.: Synthesis of highly monodisperse silver nanoparticles from AOT reverse Micelles: a way to 2D and 3D self-organization. Chem. Mater. 9, 950-957 (1997)

3. Esumi, K., Tano, T., Torigoe, K., Meguro, K.: Preparation and characterization of biometallic $\mathrm{Pd}-\mathrm{Cu}$ colloids by thermal decomposition of their acetate compounds in organic solvents. Chem. Mater. 2, 564-587 (1990)

4. Henglein, A.: Reduction of $\mathrm{Ag}(\mathrm{CN}) 2^{\prime \prime}$ on silver and platinum colloidal nanoparticles. Langmuir 17, 2329-2333 (2001)

5. Rodriguez-Sanchez, L., Blanco, M.C., Lopez-Quintela, M.A.: Electrochemical synthesis of silver nanoparticles. J Phys Chem B 104, 9683-9688 (2000)

6. Zhu, J.J., Liu, S.W., Palchik, O., Koltypin, Y., Gedanken, A.: Shape controlled synthesis of $\mathrm{Ag}$ nanoparticles by pulse sonoelectrochemical methods. Langmuir 16, 6396-6399 (2000)

7. Pastoriza-Santos, L., Liz-Marzan, M.: Preparation of PVP-protected metal nanoparticles in DMF. Langmuir 18, 2888-2894 (2002)

8. Saifuddin, N., Wong, C.W., Yasumira, A.A.N.: Rapid biosynthesis of silver nanoparticles using culture supernatant of bacteria with microwave irradiation. E-J Chem 6(1), 61-70 (2009)

9. Bhainsa, K.C., D'Souza, S.F.: Extracellular biosynthesis of silver nanoparticles using the fungus Aspergillus fumigatus. Colloids Surf B Biointerfaces 47, 160-164 (2006)

10. Willner, B., Basnar, B., Willner, B.: Nanoparticle-enzyme hybrid systems for nanobiotechnology. FEBS J. 274, 302-309 (2007) 
11. Begum, N.A., Mondal, S., Basu, S., Laskar, R.A., Mandal, D.: Biogenic synthesis of $\mathrm{Au}$ and $\mathrm{Ag}$ nanoparticles using aqueous solutions of Black Tea leaf extracts. Colloids Surf. 71(1), 113-118 (2009)

12. Bar, H., Bhui, D.K., Sahoo, G.P., Sarkar, P., De, S.P., Misra, A.: Green synthesis of silver nanoparticles using latex of Jatropha curcas. Colloid Surf A 339, 134-139 (2009)

13. Song, J.Y., Kim, B.S.: Rapid biological synthesis of silver nanoparticles using plant leaf extracts. Bioprocess Biosyst. Eng. 32, 79-84 (2009)

14. Parashar, V., Parashar, R., Sharma, B., Pandey, A.C.: Parthenium leaf extract mediated synthesis of silver nanoparticles a novel approach towards weed utilization. Dig J Nanomater Biostruct 4(1), 45-50 (2009)

15. Kotakadi, V.S., Subba Raoa, Y., Gaddam, S.A., Prasad, T.N.V.K.V., Varada Reddy, A., Sai Gopal, D.V.R.: Simple and rapid biosynthesis of stable silver nanoparticles using dried leaves of Catharanthus roseus Linn. G. Donn and its anti microbial activity. Colloids Surf B Biointerfaces 105, 194-198 (2013)

16. Subba Rao, Y., Kotakadi, V.S., Prasad, T.N.V.K.V., Varada Reddy, A., Sai Gopal, D.V.R.: "Green synthesis and spectral characterization of silver nanoparticles from Lakshmi tulasi (Ocimum sanctum) leaf extract" Spectrochim. Acta A 103, 156-159 (2013)

17. Kotakadi, V.S., Gaddam, S.A., Subba Rao, Y., Prasad, T.N.V.K.V., Varada Reddy, A., Sai Gopal, D.V.R.: Biofabrication of silver nanoparticles by Andrographis paniculata. Eur J. Chem 73, 135-140 (2014)

18. Kora, A., Arunachalam, J.: Assessment of antibacterial activity of silver nanoparticles on Pseudomonas aeruginosa and its mechanism of action. World J. Microbiol. Biotechnol. 5, 1209-1216 (2011)

19. Amin, M., Anwar, F., Janjua, M.R.S.A., Iqbal, M.A., Rashid, U.: Green synthesis of silver nanoparticles through reduction with Solanum xanthocarpum L. Berry extract: characterization, antimicrobial and urease inhibitory activities against Helicobacter pylori. Int. J. Mol. Sci. 13, 9923-9941 (2012)

20. Abboud, Y., Eddahbi, A., EI Bouari, A., Aitenneite, H., Brouzi, K., Mouslim, J.: Microwave- assisted approach for rapid and green phytosynthesis of silver nanoparticles using aqueous onion (Allium серa) extract and their antibacterial activity. J Nanostruct Chem 3, 84 (2013)

21. Jose, R.M., Jose, L.E., Alejandra, C.: The bactericidal effect of silver nanoparticles. Nanotechnology 16, 2346-2353 (2005)

22. Lok, C., Ho, C., Chen, R., He, Q., Yu, W., Sun, H., Tam, P.K., Chiu, J., Che, C.: Silver nanoparticles: partial oxidation and antibacterial activities. J. Biol. Inorg. Chem. 12, 527-534 (2007)

23. Ip, M., Lui, S.L., Poon, V.K.M., Lung, I., Burd, A.: Antimicrobial activities of silver dressings: an in vitro comparison. J. Med. Microbiol. 55, 59-63 (2006)

24. Akinde, B.E., Okeke, I., Orafidiya, O.O.: Phytochemical and antibacterial evaluations of Cassia alata leaves-extracts. Afr. J. Med. Pharm. Sci. I, 38-43 (1999)

25. Benjamin, T.V., Lanikanra, A.Q.: Investigation of Cassia alata plant used in Nigeria for the treatment of skin diseases. Q. J. crude Res. 10(2/5), 93-96 (1981)

26. Palanichamy, E., Bakthavathsalam, R., Nagarayan, S.: Wound healing activities of Cassia alata. Fitoterapia Lxii(2), 153-156 (1991)

27. Mock, J.J., Barbic, M., Smith, D.R., Schultz, D.A., Schultz, S.: Localized surface plasmon resonance effects by naturally occurring Chinese yam particles. J. Chem. Phys. 116, 6755-6759 (2002)

28. Panacek, A., Kvitek, L., Prucek, R., Kolar, M., Vecerova, R., Pizurova, N., Sharma, V.K., Nevecna, T., Zboril, R.: Silver colloid nanoparticles: synthesis, characterization, and their antibacterial activity. J. Phys. Chem. B 110, 16248-16253 (2006)

29. Zaheer, Z.: Rafiuddin: silver nanoparticles to self-assembled films: green synthesis and characterization. Colloids Surf. B 90, 48 (2012)

30. Gopinath, K., Gowri, S., Arumugam, A.: Phytosynthesis of silver nanoparticles using Pterocarpus santalinus leaf extract and their antibacterial properties. J Nanostruct Chem. 3, 68 (2013)

31. Vanaja, M., Gnanajobitha, G., Paulkumar, K., Rajeshkumar, S., Malarkodi, C., Annadura, G.: Phytosynthesis of silver nanoparticles by Cissus quadrangularis: influence of physicochemical factors. J. Nanostruct Chem. 3, 17 (2013)

32. Philip, D.: Mangifera indica leaf-assisted biosynthesis of welldispersed silver nanoparticles. Spectrochim Acta A Mol Biomol Spectrosc. 78, 327-331 (2011)

33. Kumar, K.M., Mandal, B.K., Sinha, M., Krishnakumar, V.: Terminalia chebula mediated green and rapid synthesis of gold nanoparticles. Spectrochim. Acta. A. 86, 490-494 (2012)

34. Suresh, A.K., Doktycz, M.J., Wang, W., Moon, J.W., Gu, B., Meyer III, H.M., Hensley, D.K., Allison, D.P., Phelps, T.J., Pelletier, D.A.: Monodispersed biocompatible silver sulfide nanoparticles facile extracellular biosynthesis using the $\gamma$-proteobacterium, Shewanella oneidensis. Acta Biomater. 7, 4253-4258 (2011)

35. Hoppens, M.A., Wheeler, Z.E.W., Qureshi, A.T., Hogan, K., Wright, A., Stanley, G.G., Young, D., Savage, P., Hayes, D.: Maghemite, silver, ceragenin conjugate particles for selective binding and contrast of bacteria. J. Colloid Interface Sci. $\mathbf{4 1 3}$ 167-174 (2014)

36. Ruparelia, J.P., Chatterjee, A.K., Duttagupta, S.P., Mukherji, S.: Strain specificity in antimicrobial activity of silver and copper nanoparticles. Acta Biomater. 4, 707-716 (2008)

37. Lukman, A.I., Gong, B., Marjo, C.E., Roessner, U., Harris, A.T.: Facile synthesis, stabilization, and anti-bacterial performance of discrete Ag nanoparticles using Medicago sativaseed exudates. J. Colloid Interface Sci. 353, 433-444 (2011)

38. Caceres, A., Menendez, H., Mendez, E., Cohobon, E., Samayao, B.E., Jauregui, E., Peralta, E., Carrillo, G.: Antigonorrhoeal activity of plants used in Guatemala for the treatment of sexually transmitted diseases. J. Ethnopharmacol. 48, 85-88 (1995)

39. Rout Rajesh, W., Lakkakula Jaya, R., Kolekar Niranjan, S., Mendhulkar Vijay, D., Kashid Sahebrao, B.: Phytosynthesis of silver nanoparticle using Gliricidia sepium (Jacq.). Curr. Nanosci. 5, 117-122 (2009)

40. Kim, J.S., Kuk, E., Yu, K.N., Kim, J.H., Park, S.J., Lee, H.J., Kim, S.H., Park, Y.K., Park, Y.H., Hwang, C.Y., Kim, Y.K., Lee, Y.S., Jeong, D.H., Cho, M.H.: Antimicrobial effect of Silver nanoparticles. Nanomed. Nanotechnol. Biol. 3, 95-101 (2007)

41. Sondi, I., Salopek-Sondi, B.: Silver nanoparticles as antimicrobial agent a case study on E.coli as a model for Gram-negative bacteria. J. Colloid Interface Sci. 275, 177-182 (2004)

42. Feng, Q.L., Wu, J., Chen, G.Q., Cui, F.Z., Kim, T.N., Kim, J.O.: A mechanistic study of the antibacterial effect of silver ions on Escherichia coli and Staphylococcus aureus. J. Biomed. Mater. Res. 52, 662-668 (2000)

43. Siva Kumar, V., Nagaraja, B.M., Shashikala, V., Padmasri, A.H., Madhavendra, S.S., Raju, B.D., Rama Rao, K.S.: Highly efficient $\mathrm{Ag} / \mathrm{C}$ catalyst prepared by electrochemical deposition method in controlling microorganisms in water. J. Mol. Catal. A. Chem. 223, 313-319 (2004)

44. Juan, L., Zhimin, Z., Anchun, M., Lei, L., Jingchao, Z.: Deposition of silver nanoparticles on titanium surface for antibacterial effect. Int. J. Nanomed. 5, 261-267 (2010) 